\title{
Editorial
}

\section{The role of technology in the workplace marketing of pensions}

The role of the workplace in delivering financial services to individuals is expanding. Environmental drivers include: obligatory stakeholder pension provision, increased adoption of flexible benefits packages and maturing IT infrastructure. Along with a tight labour market and reduced access to financial advice for the mass market, the role of the employer and the workplace as sources of information and purchase power make sense.

At least four key stakeholders are identified as being part of the workplace marketing process: product/service provider, intermediary, employer, employee. From the employer's perspective workplace marketing offers a cost-effective way of providing services to employees and a means of enhancing the overall value of the benefits package. From the employee's perspective workplace marketing can offer increased access to goods and services that are of value to the individual, often arranged at competitive rates. For product providers and intermediaries, workplace marketing offers the advantage of access to a broad and captive customer base.

Within the process of workplace marketing there are issues concerning what to provide to employees and how it should be provided, the role of the employer and other stakeholders in the process (particularly in the case of complex financial services), how information and advice should be imparted and the expectations and perceptions that employees have of their employer in this respect.
Technology, in the form of the internet and intranets, has facilitated the process of workplace marketing, but has also created a new set of challenges. There is a need for research that highlights how best to maximise the benefits and overcome the challenges.

Set against this context, a small number of qualitative focus groups were conducted among members of both defined contribution and defined benefit pension schemes within the private and public sectors.

Four focus groups were conducted in April and May 2005. Two focus groups were held at a public sector organisation operating a defined benefit pension scheme and two focus groups were held at a private sector organisation operating a defined contribution scheme. A total of 24 individuals participated, 10 female and 14 male, and each group contained a wide range of ages. All participants used the internet in their job and many made extensive use of the internet, describing themselves as experts.

In each focus group participants discussed their current use of the internet, their current use of their occupational pension scheme website, the specific website features they valued and the long and short-term benefits that they believed they would gain from using the website.

All participants found the internet useful for both work and personal use, describing it as their 'right arm' and finding it hard to imagine a time before it existed. 
Participants reported that internet use saved them time in a variety of ways and provided easy access to information which in turn enabled them to increase their knowledge and make informed comparisons and choices. In all groups attitudes towards the internet were broadly positive, however, the public sector groups were more critical of its espoused benefits. They questioned the accuracy of online information, reported experiencing problems with purchases and complained that websites generally offered standardised solutions. They also expressed dissatisfaction that websites often only allowed for e-mail contact and did not contain information such as addresses or telephone numbers. This was perceived as an attempt to discourage the individual from making contact with a person or office, thus keeping them at 'arm's length'.

In terms of the extent of use of pension scheme websites, the groups showed varying levels of engagement with the website. On the whole, it would appear that the primary factor determining use and perceived usefulness of the website is the nature of the pension scheme (whether it is defined benefit or defined contribution). Technological factors and the experience and perceived ease of use of the technology seem to be secondary determinants.

Members of the defined benefit scheme acknowledged that there were limited ways in which they could become involved in their pension, other than deciding to make additional voluntary contributions. They felt that the decision was taken out of their hands and they relied very much on their employer to make the right decisions on their behalf:

'We are basically passive. They do it, we just hope they do it right.'

The defined benefit scheme members who had looked at the site found it 'straightforward and easy'. Others were aware of the site through communication, but felt it held little of interest to them:

'I am sure they advertise it in the material they send to us, but to be honest I have never looked at it. It is not something that would immediately grab me.'

It would seem that the passive role adopted by many defined benefit scheme members inhibits even a perception of the usefulness of self-service technology in this context.

In contrast, the private sector employees had been compelled to use their pension website as part of a shift from a defined benefit scheme to a defined contribution scheme. In fact, joining the new pension scheme was only possible via the website. While this meant that the members of the defined contribution scheme were more likely to have made use of the pension website, a comment by one of the participants suggests that the attitude towards pension websites is perhaps not too dissimilar from participants in the public sector groups:

'I think the difference with the pension website [compared to other sites] is, I will go on to it with a slightly ambivalent attitude ... rather than a positive attitude as a starting point.'

The nature of the defined contribution scheme means that members can elect to have more involvement in their pension and make choices regarding funds in which to invest. The extent of use of the website in terms of such activities as fund switching thus depended on the individual's own interest in their pension and their desire to manage it actively themselves. The website provided the vehicle by which to facilitate this.

In each of the focus groups participants 
identified specific website features that they valued for a pension website. In the public sector/defined benefit groups there was a focus on information provision. Pension information was desired in order to:

- understand how to gain maximum benefit from what was considered to be a 'Rolls Royce' scheme

- facilitate convenient and easy access to scheme terms and conditions that, in paper-based form, were often filed away and rarely consulted

- improve understanding of the pension and pension-related issues and enable individuals to have more knowledgeable conversations in faceto-face advice situations.

In the private sector/defined contribution groups the emphasis was slightly different, not on information per se but information that can be used to facilitate action. Thus, information features were desired in order to achieve three broad objectives:

- To set a pension target and work out a path to achieve it

- To gain assurance that investment decisions made via the web had been placed in the right funds

- To develop the ability to exercise investment choice in an informed way.

To meet pension management needs participants wanted the ability to make quick updates to personal details. The facility to switch funds was debated, with some participants arguing for immediate transfer and others stating that due to the long-term nature of pensions immediate transfer was not necessary. In many cases there was the perception that a web-based facility means that any changes are actioned immediately. The long-term nature of pensions and the mechanisms surrounding fund switches, for example, were perceived to be at odds with the immediacy of the web and not understood by all.

Both groups desired specific features such as a jargon buster, a general planning tool/modeller, a personalised projection tool and a full individual contribution history. In fact when participants were asked what they would like to see online in an ideal world discussion centred on the tools that would allow the individual to predict their final pension outcome. Differences between the groups were that the private sector/defined contribution participants wanted comparative fund information and annuity rate information; whereas the public sector/defined benefit participants wanted features such as information on ethical investments, information on scheme processes, member case histories and information on the impact of legislative change.

In the short term, both groups identified the internet as making individual pension information accessible which in turn would motivate them to take a closer interest. As one public sector participant stated:

'Rather than having to wait ... you could do it at 12 o'clock one afternoon if you had a mind to, so I would be more inclined to keep more up-to-date with my pension really.'

The long-term benefits were less clear to participants in the public sector/defined benefit group. One public sector participant remarked that he could not see any value added beyond enhanced convenience and immediacy of information provision. In the private sector/defined contribution groups the internet was felt to give greater control in some cases, however, the absence of any individual long-term strategy for pensions via the website resulted in low perceptions of the utility of the internet. Several 
individuals referred to pensions as a 'black hole'.

Many organisations have either developed or are in the process of developing websites for their occupational pension schemes. It is clear that there is a need for such websites, but not all of them meet the needs of scheme members. This small-scale research has shown that scheme member needs differ according to the nature of the scheme as well as their own interest in pensions and willingness to engage in self-service technology.

The over-riding benefit to scheme members seems to be that a website should be able to assist them in understanding: 1 . their current position; 2. their future desired position; 3 . how to get there.

Tina Harrison Managing Editor 